\title{
Reflexões sobre o ensino de história: discussão de algumas proposições de Jacques Le Goff
}

Joana Neves*

\section{RESUMO}

Esse artigo considera a importância da repercussão das concepções da Nova História sobre o ensino de história, no Brasil, a partir da década de 70 , entendendo que, por isso, impõe-se a necessidade de análise dos efeitos dessa repercussão nos diferentes aspectos e níveis de ensino. Nesse sentido, buscou-se enunciar algumas questões fundamentais para essa análise, levantadas a partir de proposições de Jacques Le Goff, não por acaso, um dos mais expressivos representantes da Nova História, sobejamente conhecido pelos estudiosos brasileiros. Para tanto, adotou-se o seguinte procedimento: apresentação de cada uma das proposições, extraídas da obra História e Memória, e discussão das mesmas, relacionando-as com o ensino, considerado como produção de conhecimento. A questão central, resultante do conjunto das preposições discutidas, é a constatação da necessidade de se discutir o ensino, tanto quanto a pesquisa, à luz dos pressupostos teórico-metodológicos e da epistemologia da história. No final, não como conclusão mas como provocação ao debate, são apresentadas, quase como máximas estabelecidas, as linhas gerais das diferentes etapas escolares do ensino de história, segundo a atual legislação brasileira.

Palavras-chaves: ensino de história, nova história, produção do conhecimento histórico, relação ensino/pesquisa.

As concepções teórico-metodológicas da chamada Nova História, originada dos Annales, repercutiram em muitas propostas e práticas de ensino de história. E essa repercussão ocorreu não só na França, seu lugar de origem. No Brasil, notadamente em escolas dos grandes centros urbanos, a partir da década de 70, um grande número de propostas de mudanças do ensino de história apresentaram-se sob a égide da Nova História buscando-se, com essa fundamentação, assegurar o caráter inovador das novas propostas.

\footnotetext{
* Professora universidade Federal de Paraíba
} 
No entanto, não se verificaram, até agora, na área de história, ou, mais precisamente, entre os historiadores de ofício, debates que levassem ao esclarecimento dos reais significados da referida repercussã $0^{1}$. A esse respeito, algumas questões precisariam se colocadas. Por exemplo: em que medida os postulados da Nova História - pensados para a pesquisa - são adequados às diferentes etapas do ensino, sobretudo as iniciais e elementares (no caso da legislação brasileira atual, nos ensinos fundamental e médio)? Quais são os procedimentos teórico-metodológicos e didático-pedagógicos necessários para assegurar essa adequação? E, principalmente, quais são as efetivas inovações propiciadas pelas novas propostas e como essas inovações poderão ser aferidas?

Esse artigo, elaborado a partir da leitura do livro de Jacques Le Goff História e Memória, pretende ser uma contribuição para a discussão dessas questões, tendo como ponto de partida o pensamento de um dos mais expressivos representantes da Nova História ${ }^{2}$.

\section{Le Goff e 0 ensino de história}

A leitura do item História, dessa obra de Le Goff sugere interessantes questões ligadas ao ensino de história, algumas colocadas explicitamente pelo autor.

A primeira e importante questão é da própria relação entre epistemologia e ensino de história.

Essa relação seria descabida, segundo as concepções tradicionais de ensino. Sendo concebido como o espaço da transmissão do conhecimento, o ensino não comportaria discussão de questões epistemológicas e nem de teoria da história, consideradas específicas e reservadas ao espaço da pesquisa que tem como objeto a produção do conhecimento, portanto, natural e obviamente ausente do ensino.

1 Margarida Maria Dias de Oliveira, em tese de Doutorado, defendida em março/2003, analisa o processo de constituição do ensino de história em objeto de pesquisa. Nessa análise a Autora identifica, nesse processo, a prevalência das questões pedagógicas em detrimento de um debate que, a ser feito por historiadores, deveria dar conta dos aspectos teóticos e metodológicos específicos da produção do conhecimento histórico, em sua ligação com ou ensino. Dito de outro modo, seria preciso reconhecer o caráter intrinsecamente educativo do conhecimento histórico para, então, estabelecer as características do seu ensino, os diferentes níveis educacionais.

2 LE GOFF, Joacques. História e Memória. Trad. Bernardo Leitão e outros. 3ed. Campinas: Editora da UNICAMP, 1994. 
A partir da década de 70, no âmbito da educação brasileira, verificaramse tendências no sentido de revisão de noções e conceitos fundamentais tanto do ensino, de um lado, como da ciência da história, de outro. Assim, passados mais de vinte anos, novas concepções substituíram as tradicionais, nos dois campos. 0 ensino deixou de ser considerado mera transmissão de conhecimento e foi guindado à posição de área de produção do conhecimento e, neste sentido, equiparado à pesquisa. A ciência dà história, por sua vez, teve seus pressupostos tão questionados a ponto de, atualmente, em certa medida, negar-se até a sua condição de ciência.

Desse modo, a discussão epistemológica acabou por se tornar central para a história; está em jogo, afinal, a sua própria definição como campo de conhecimento.

0 ensino, também, para mudar seu status, ou seja: deixar de ser a desprestigiada área da transmissão para integrar o campo superior da produção do conhecimento, precisou rever seus pressupostos e suas práticas.

No caso do ensino de história, com o duplo debate, gerado pela dupla tendência de revisão, verifica-se um grande problema: justamente o fato dele ter acontecido de um lado e de outro! Ou seja: discute-se o ensino como produção de conhecimento mas, em geral, não se leva em conta 0 debate epistemológico. Disso resulta que algumas importantes inovações metodológicas no ensino foram, e continuam sendo, implantadas sem qualquer relação com as inovações historiográficas e, às vezes, até em oposição a essas inovações ou, o que é bem pior: aplicando essas inovação de forma equivocada, cometendose, sobretudo, a impropriedade de se adotar nas etapas elementares do ensino pressupostos aplicáveis à pesquisa de ponta.

Jacques Le Goff não se propõe, em sua obra, a promover o encontro dos dois debates, mas sugere instigantes possibilidades ao enunciar algumas proposições relativas ao ensino de história no exato momento e no mesmo patamar em que reflete sobre as atuais condições de elaboração da ciência da história.

A partir dessas proposições, podem ser destacadas algumas questões por meio das quais é possível apontar alguns aspectos da relação, que se faz necessária, atualmente, entre 0 ensino - concebido agora como produção de conhecimento - e a epistemologia da história.

As questões, definidas pelas proposições escolhidas, dizem respeito a: 
- $\quad$ o ensino e a revisão da história tradicional;

- o factual e a periodização no ensino de história;

- $\quad$ o ensino de história: tarefa para historiadores;

- a importância e a necessidade do ensino de história.

Para tratar essas questões adotou-se o seguinte procedimento: apresentação da proposição do Autor e análise da mesma, tendo como referência a possível articulação entre os pressupostos epistemológicos enunciados e as possibilidades do ensino, tomado como área de produção do conhecimento.

É preciso esclarecer que a discussão refere-se ao ensino de história destinado ao conjunto das pessoas comuns e não aos que se destinam à profissionalização na área. Isto é: trata-se do ensino nos níveis fundamental e médio e não do ensino superior, no qual, por suposto, a relação com a epistemologia deveria estar estabelecida, por definição.

\section{As proposições de Le Goff}

1. 0 ensino e a revisão da história tradicional.: "É desejável que a informação histórica, fornecida pelos historiadores de ofício, vulgarizada pela escola (ou pelo menos deveria sê-lo) e os mass media, corrija esta história tradicional falseada." (p. 29)

Ao discutir a relação entre história e memória, Le Goff reconhece a existência de "duas histórias": a que é construída pela memória coletiva e a dos historiadores. Sendo a primeira falseada, por ser mística, deformada e anacrônica, a segunda teria a função de corrigi-la, uma vez que a história (a feita pelos historiadores) pode esclarecer a memória e retificar seus erros.

Se ao pensamento de LeGoff acrescentar-se 0 de Marc Ferro, que desenvolve a noção de história vigiada, ${ }^{3}$ seria possível supor a existência de um confronto entre a subjetividade e a parcialidade da memória e a objetividade e imparcialidade possíveis (ou desejáveis) na elaboração do conhecimento histórico. Todos os termos dessa afirmação são discutíveis, e Le Goff o reconhece; porém, ainda assim, acaba por afirmar a possibilidade de uma ação corretiva da história sobre a memória por meio do exercício da crítica.

3 FERR0, Marc. A História Vigiada. Trad. Doris Sanches Pinheiro. São Paulo: Martins Fontes, 1990. 
Seria, justamente, a crítica que dotaria a história, feita pelos historiadores, da faculdade de corrigir as visões tradicionais que uma sociedade, num determinado tempo, constrói a cerca de seu passado de modo a submeter 0 presente a estereótipos e preconceitos que correspondem mais a idealizações do que ao registro, mesmo que distorcidos, dos fatos e feitos dessa sociedade.

Em outro sentido é possível considerar a história tradicional, construída pela memória coletiva, falseada pela afirmação do senso comum, generalizado a partir dos diversos meios informais de divulgação e de transmissão de informações, e que se constitui na modalidade mais popular de história.

0 ensino (esta discussão não está contemplando os mass media) que, para Le Goff, deve tratar da informação histórica fornecida pelos historiadores de ofício, teria a responsabilidade de colocar a sociedade, como um todo, diante de si mesma, até mesmo para (re)conhecer suas limitações. Tarefa extremamente difícil!. Se a história, como campo de conhecimento, é vigiada, mais ainda o é o ensino. Aí a vigilância se exerce, formal e informalmente, de modo a assegurar a construção não exatamente de um conhecimento sobre a sociedade em que se vive, mas de uma idéia daquilo que se pretende que seja essa sociedade.

Formalmente a vigilância sobre o ensino se dá por meio de leis, regulamentos, programas, orientações metodológicas e, sobretudo, atualmente, avaliações oficiais; esta vigilância representa uma forma direta de controle dos poderes instituídos sobre a formação das pessoas. Mesmo quando disfarçado pela retórica da crítica e da afirmação da busca de liberdade o controle, por meio do ensino, valendo-se da história tradicional falseada, visa à conformação, adequação e, por fim, a submissão das pessoas ao modelo de sociedade requerido pelo exercício e manutenção dos referidos poderes. Seria mais próprio e, principalmente, mais rico de significados, usar, em lugar de pessoas a palavra indivíduos, pois essa é a expressão carregada da ambigüidade que se expressa na tensão que existe entre os agentes da história e os processos construídos por sua atuação ou, dito de outro modo, entre o ser, único e dotado de liberdade, e a sociedade, comum e imprescindível para a existência deste ser único e original.

Informalmente a vigilância e o controle deveriam ser exercidos pelos setores sociais mais diretamente interessados e alcançados pela atuação das agências de 
ensino (a escola) isto é, desde a família, em primeiro lugar, até os grupos mais específicos, defensores das mais diversas manifestações culturais que se definem como tradições. No Brasil, porém, parece se observar um grande distanciamento entre a escola e o conjunto da sociedade, atestando não uma irrestrita confiança, como poderia supor um professor otimista, mas um alheamento decorrente de um profundo desconhecimento sobre o que é, o que se faz e o que se esperar da escola. A escola brasileira, desde a ditadura militar e, tudo indica, sem grandes alterações ná chamada redemocratização tem sido, cada vez mais, solicitada a empreender políticas e práticas de assistência social (do tipo: fornecer, por meio da merenda escolar, a única alimentação que a criança recebe ou evitar que 0 menor, solto na rua, se torne um marginal), sem que se explicitem ou, o que é pior, sem que se cobrem, os conteúdos a serem desenvolvidos. Enfim, as expectativas com relação ao ensino e aspirações intelectuais deram lugar aos temores e angústias diante dos problemas concretos de subsistência.

Assiste-se até, mais recentemente, a uma total inversão: a escola passando a ser um lugar perigoso (para alunos e professores), onde rondam os flagelos sociais mais em voga: drogas e violência que, de resto, sintetizam os demais.

Assim sendo, se não uma vigilância, mas um contraponto para o ensino da história feita pelos historiadores vem sendo feito pelos ... mass media, que Le Goff, tendo como referência, com certeza, a televisão francesa, esperava ter como aliados na correção da história tradicional falseada, construída pela memória. Basta ver como foi colocada a comemoração dos 500 anos do descobrimento do Brasil pela TV Globo, a maior e mais assistida rede de televisão brasileira. Em vez de corrigir a memória, o que se fez foi reforçá-la até mesmo criando, artificialmente, uma inexistente memória para fatos e feitos remotos que, há muito tempo, deixaram de ser "rememorados" por homens e mulheres comuns.

Apesar de todos esses obstáculos e contratempos há um evidente ou, pelo menos, propalado, esforço por parte do ensino de história de corrigir a história tradicional falseada. Mas, surpreendentemente, não no sentido referido por Le Goff. A correção que se busca é a do falseamento produzido pela história tradicional... dos historiadores. E o que parece ironia é que um dos meios empregados nessa correção é, justamente, buscar o auxílio da memória! Há um entendimento, generalizado entre os educadores, incluindo-se os professores 
de história, segundo o qual existe uma história produzidas por historiadores, tradicional, que foi guindada à condição de história oficial, na qual os homens comuns, os vencidos, os marginais, os que resistiram ao poder, não têm lugar. Por isso, seria preciso resgatar a história desses novos agentes, escamoteada pela ciência, buscando-a na memória coletiva, representada, no caso, pelos alunos, seus pais, seus avós, bem como outros membros da comunidade, ats então munca ouvidos pelos pesquisadores.

É bem verdade que os aportes para essa revisão são fomecidos pelos próprios historiadores. Ainnal, a história, feita pelos historiadores, nãoé sempre a mesma. $\Lambda$ existência de dias histórias, apontada na proposição de Le Goff, pode até ser aceita; atualmente, porém, é muito difícil aceitar-se, a oposição entre ambas. Afinal, tradição e falseamento podem ser identificados tanto em uma como em outra. A questão parece ser a da inevitável e, quem sabe, necessária, relação entre as duas modalidades de construção do conhecimento histórico. E, assim, o ensino recoloca a questão epistemológica.

2. 0 factual, a periodização e 0 ensino de história: "Certamente que a sucessividade que constitui o estofo do material histórico obriga a conto um lugar que me parece fundamentalmente de ordem pedagógica. Corresponde simplesmente à necessidade que há, em história, de expor o como, antes de procurar o porquê, o que coloca o conto na base da lógica do trabalho histórico. (p. 35) (...) A periodização é o principal instrumento de inteligibilidade das mudanças significativas. "(p. 47).

A primeira e fundamental observação é que Le Goff, apesar de se referir à ordem pedagógica da questão factual (do conto), não está discutindo o ensino e sim a pesquisa, a produção do conhecimento histórico, no seu sentido mais restrito e específico.

Ele aponta para os imprescindíveis elementos de ordenação do conhecimento histórico: o que aconteceu? como aconteceu? quando, em que ritmo aconteceu? sem os quais não se constroem os processos, as explicações gerais. Isto é, sem os quais não se faz uma ciência da história.

Se isso é verdade para a pesquisa, mais ainda o é para o ensino.

No entanto é exatamente sobre esse ponto que incidiu, e ainda incide, a 
revisão da chamada história tradicional, supostamente realizada pelo ensino de história no Brasil. A palavra de ordem dessa revisão foi justamente: promover a superação do factual e do cronológico no ensino de história. Era preciso abandonar aquele tipo de ensino que fazia da história um rol de nome/fato/ data a ser decorado pelos alunos. Rotulada de positivista, a história, ensinada desta forma, recebeu uma série de epítetos, todos considerados negativos: do ponto de vista metodológico, factual, descritiva, narrativa, cronológica e, do ponto de vista ideológico, oficial, dos vencedores, dos grandes homens. Além do mais, atribuía-se a essa abordagem da história a existência de alguns graves problemas sendo os mais recorrentes o desinteresse pela história e o caráter alienante da disciplina escolar que a tem como matéria ou objeto. A história juntava, então, o desagradável ao inútil; na linguagem dos estudantes: era chata e não servia para nada. Durante duas décadas, a de 70 e a de 80 , houve um enorme esforço de crítica apontando as falhas e os equívocos desta história tradicional, ensinada nas escolas, e a busca de soluções para esses graves problemas.

0 materialismo histórico, tratado, de forma bastante simplista, como 0 oposto do positivismo, foi o principal suporte para a crítica e para a construção das soluções consideradas adequadas.

Sem dúvida, simplificações e exageros à parte, foi um grande avanço. No entanto, teve preços muito altos. No que diz respeito à proposição de Le Goff, esse avanço levou de roldão a ordenação factual e cronológica, promovendo a equivocada explicação do porquê antes ou mesmo sem elucidação do como. E, o que talvez tenha sido pior, a perda do conto, da narrativa, como forma de exposição histórica. A narrativa de fatos construídos e ordenados cronologicamente, deu lugar a um enunciado "crítico", apresentado como construção de processos, na maior parte das vezes, sem sujeitos, sem dados ou informações, esquemáticos, quando não dogmáticos, o que, com certeza, não contribuiu para despertar o interesse pela história.

No final dos anos 80 , sob o impacto da crise do pensamento marxista e do fim dos regimes socialistas soviéticos, a ele relacionados, o ensino de história começou a ser cobrado por essas distorções.

Porém, no final dos anos 90 e início do novo século, não se trata mais de recuperar o factual e o cronológico como ordenadores de uma narrativa 
histórica coerente. Abordagens que se pretendem vinculadas à Nova História, simplesmente, suprimem o fato da existência da história. É justamente para essa nova forma de distorção que a proposição de Le Goff alerta.

A eliminação do fato, em história, acarreta para 0 ensino, nas fases iniciais e elementares, um esvaziamento do conteúdo, tão ou mais pernicioso do que as distorções positivistas e marxistas. A monótona recitação da interminável lista de nome/fato/data, que já se pretendeu substituir pela enunciação de processos impessoais, corre o risco, agora, de ser abafada por estranhos ruídos de um discurso vazio. Assim, impede-se, nos termos de Le Goff, que a inteligibilidade das mudanças significativas, possível de se obter por meio do conhecimento histórico, fique ao alcance dos jovens.

3. 0 ensino de história: tarefa para historiadores:: "Mas deveríamos todos ser historiadores? Não reclamo poder para os historiadores fora do seu território, a saber, o trabalho histórico e o seu efeito na sociedade global - em especial, no ensino." (P. 51).

A terceira proposição escolhida é a resposta para os problemas levantados pelas duas primeiras.

Se 0 ensino é aceito como produção do conhecimento, obviamente ele é espaço para a afuação de especialistas, isto é, profissionais capazes de darem conta, sistematicamente, dos problemas, inclusive os de ordem epistemológica, colocados pela produção do conhecimento na sua área.

Essa proposição, porém, não é acatada unanimemente. Uma certa exacerbação pedagógica, que vem dominando a educação brasileira desde a década de 70, ao contrário, tem provocado muita celeuma em torno da questão da formação dos professores - os profissionais responsáveis pelo ensino - os de história entre eles. Mesmo aceitando a idéia de que o ensino é espaço da produção e não da mera transmissão do conhecimento, há quem defenda a idéia de que o professor, sendo antes de tudo um educador, deve ter sua formação centrada nos elementos pedagógicos. Plagiando uma das formulações de Le Goff, há quem defenda que, no ensino, como fazeré mais importante do que o que fazer. Ou seja, estabelece-se a prevalência da forma sobre o conteúdo em um processo que, segundo se afirma à exaustão, deve ser de produção do conhecimento. 
Essa situação é ainda mais grave na primeira fase do ensino fundamental (as quatro primeiras séries ou os dois primeiros ciclos), para a qual está programado (pelos Parâmetros Curriculares Nacionais) um alentado conteúdo de história mesmo estando o ensino a cargo da professora polivalente que, quando tem nível superior, é formada em Pedagogia.

Existe, teoricamente, uma saída para esse impasse.

É preciso, para considerá-la, retomar a segunda proposição de Le Goff, aqui analisada, e questionar a eventual separação entre o como e o porquê que ela sugere. Amitindo-se que esses dois termos (ou as duas operações: narrar e explicar) se interpenetram mais do que se superpõem é possível, também, admitir que o profissional do ensino de história deverá ser o historiador, sem dúvida, porém, dotado de formação pedagógica suficiente para adequar a produção do conhecimento histórico (o seu território específico) às exigências da educação, um território mais amplo e diversificado, onde a história ocupa um lugar imprescindível, como se verá no próximo item, sem, contudo, preenche-lo completamente.

4. A importância e a necessidade do ensino de história: “(...) mas reivindicar com força a necessidade da presença do saber histórico em toda a ação científica ou em toda praxis. No domínio da ciência, da ação social ou política, da religião ou da arte - para considerar alguns domínios fundamentais - , esta presença do saber histórico é indispensável. "(p. 144)

Saber história é imprescindível, em todos os domínios fundamentais da ação humana. É o que diz Le Goff, nesta proposição. Concordando com isso é preciso reconhecer, então, que o ensino de história não pode estar ausente do processo educacional.

0 ensino de história, porém, exige o tratamento de todas as questões ligadas à produção do saber histórico. 0 que equivale a afirmar que o ensino de história coloca questões de ordem teórica, metodológica, enfim, epistemológica, até bem pouco tempo, consideradas exclusivas da pesquisa. Dito de outra forma: a história, como matéria escolar não deixa de ser história ciência ... ou , se a chamada crise dos paradigmas persistir, a modalidade de conhecimento formal que vier a ser definida. Com a palavra os especialistas em epistemologia da história. 


\section{Conclusão}

Chamar a este item final de conclusão é propaganda enganosa. 0 que vai ser apresentado é apenas um conjunto de provocações sobre quais e como deveriam ser as etapas do ensino de história, para dar conta de todas as questões colocadas a partir das proposições de Le Goff.

\section{Educação básica}

A Educação Básica, comportando três etapas de ensino, corresponde ao que deveria ser a educação/formação geral do cidadão comum, isto é, a educação a que o povo todo teria direito. Em relação ao conhecimento histórico cada uma das etapas deve contribuir com um tipo de formação que possibilite a esse cidadão comum, no final do processo educativo formal/escolar, ter uma visão crítica da realidade social na qual ele vive e atua.

Um rápido panorama dessas etapas pode ser traçado da seguinte maneira:

Ensino Infantil. Ninguém teve, ainda, a ousadia de propor alguma forma sistemática de ensino de história para esse nível educacional. E entendo que isso está correto. 0 aprendizado da história exige amadurecimento cognitivo e intelectual que a criança tem o direito de não ter.

Ensino Fundamental. Este nível tem duas fases: a primeira, composta por quatro séries anuais ou dois ciclos, cada um de dois anos; prevê-se nessa etapa, o ensino de noções básicas para o conhecimento histórico. Isso pode (deve) ser considerado impróprio, considerando-se a faixa etária da clientela: crianças de 6 a 10 anos. Para essa etapa a provocação é: aprender história é coisa para gente grande. Criança brinca lá fora. Não se pode ignorar, evidentemente, que houve significativas mudanças no ensino (não só de história) nessa fase escolar. Houve, sobretudo, um grande avanço, quantitativo e qualitativo, na produção de materiais didáticos, livros e outros, colocados à disposição de alunos e professoras. Contudo, não se pode admitir que essa fase promova alguma terminalidade para o estudo da história, como parecem pretender os Parâmetros Curriculares Nacionais propostos para a área. Sem dúvida, as crianças têm muito mais potencialidade cognitiva do que supunha a escola tradicional; mas ser capaz de se compreender como ser social, agente do processo histórico ... aos dez anos (!!) não parece ser possível. Pelo menos, não seria justo com as crianças. A elas deveria, ser assegurado, antes de tudo, o direito à infância. 
A segunda fase, da quinta à oitava série, comporta um vastíssimo programa oficial de história. A provocação: aprender história é uma grande aventura na qual garotos e garotas podem embarcar. Dito de outro modo: o ensino de história, nesta etapa deve ser factual e cronológico; deve contar o que aconteceu, como aconteceu, formulando explicações para o porque aconteceu, na medida em essa explicação está inserida na narrativa de 0 que e como aconteceu.

Argumentos em favor dessa posição podem ser buscados na própria Nova História, provenientes, igualmente, do pensamento de Jacques Le Goff. Afirma ele:

É preciso reduzir a história-narrativa a apenas um meio entre outros da pedagogia no ensino escolar e da divulgação. A esse respeito, gostaria de lembrar o grave erro de compreensão que levou certos funcionários animados pelas melhores intenções do mundo, principalmente na França e na Bélgica, na década de 70 e no início da de 80 , a quererem introduzir nos programas escolares o que eles acreditavam ser a nova história. Essa história é, com frequiência, o produto de uma pesquisa de ponta que não pode ser transferida ao ensino de imediato e tal como é. Seja como for, se é desejável que o espírito da nova história possa se encontrar no ensino e na divulgação, é preciso adapta-lo a seus destinatários não-especializados e carentes de conhecimento. Um mal-entendido particularmente surpreendente produziuse no domínio da cronologia, onde a introdução de novas concepções do tempo e da duração em história levou, às vezes, a uma quase liquidação da cronologia, ao passo que esta continua sendo um conjunto de referências que sem dúvida deve ser enriquecido, flexibilizado, modernizado, mas que permanece fundamental para o próprio historiador, para os jovens e para o grande público. ${ }^{4}$

Ensino Médio. Essa etapa de ensino é ainda, apesar de todas as reformulações, vítima da indefinição entre a formação geral e a formação técnica profissional. De todo modo essa indefinição não evita a pressão do vestibular. As muitas reformas educacionais, apesar de todas as formulações pedagógicas em contrário, não conseguiram modificar o caráter basicamente propedêutico do sistema educacional brasileiro. Aos concluir o ensino médio 0 que se pretende é entrar na universidade. Em nome disso, já foram formuladas propostas por força das quais o ensino de história corre até o risco de desaparecer. No entanto é exatamente nessa fase que a história pode produzir todos os seus 
efeitos, no sentido de fundamentar as ações humanas e de tornar as pessoas conscientes da sua condição de ser social agente do processo histórico. A provocação agora é: aprender história é fazer história, e ninguém vai se livrar disso. Nessa fase o ensino de história dever ser temático. Essa modalidade de ensino, deixando de lado programas tão artificiais quanto oficiais, é aquela que se organiza a partir das características, condições e interesses, dos próprios alunos. É a maneira mais adequada para se relacionar o estudo de história e a vida vivida, no exato momento em que se vive. É a modalidade de ensino que supõe a identificação dos seus agentes (alunos e professores) com Percival - o que deve saber por a questão - superando Édipo o que fornece a resposta. Para começar, essa modalidade de ensino poria em questão as regras de acesso à universidade.

Ensino Superior. Sendo a etapa de formação do profissional de história - do historiador - (em tempo: o professor de história é, segundo nossa concepção, um historiador capaz de exercer o magistério e não um outro profissional) esse é o espaço da produção do conhecimento, no qual ensino e pesquisa são faces de uma mesma moeda, no qual, portanto as questões epistemológicas estariam no núcleo do curso. Para essa fase a provocação colocada é: aprender/ensinar história é produzir conhecimento histórico. Só é possível ser professor de história sendo pesquisador. Sem vice-versa.

Uma consideração final se impõe. As discussões aqui apresentadas dizem respeito a um debate nacional que vem sendo realizado por especialistas, quer de história, quer de educação, em eventos que reúnem, em geral, pessoas interessadas e que, em muitos casos, estão discutindo seus próprios projetos de pesquisa. Por isso não é seguro que as colocações e proposições aqui defendidas reflitam a realidade das salas de aula, pelo menos da maioria delas. Se se perguntar a um estudante comum, de uma escola comum, o que ele aprende em história, muito provavelmente, se ele for bom aluno, haverá uma enumeração de ... nome! fato! data!

Há muito que fazer no ensino de história. Buscar a contribuição da epistemologia da história, tendo como referências as proposições de Le Goff, pode ser de grande valia.

\footnotetext{
4 LE GOFF, Jacques. A História Nova. Trad. Eduardo Brandão. São Paulo: Martins Fontes; 1993; p. 6-7.
} 


\title{
Bibliografia
}

FERRO, Marc. A História Vigiada. Trad. Doris Sanches Pinheiro. São Paulo: Martins Fontes, 1990.

LE GOFF, Jacques. A História Nova. Trad. Eduardo Brandão. São Paulo: Martins Fontes; 1993; p. 6-7.

LE GOFF, Joacques. História e Memória. Trad. Bernardo Leitão e outros. 3ed. Campinas: Editora da UNICAMP, 1994

\section{Reflections on history teaching: discussion of some propositions from Jacques Le Goff}

\begin{abstract}
This article considers the importance of the conceptions of the New History repercussion on the history teaching, in Brazil, starting from the decade of 70, understanding that, for this, the need for the analysis of the effects of that repercussion is imposed, in different aspects and teaching levels. In that sense, it was looked for to enunciate some fundamental subjects for that analysis, raised from propositions of Jacques Le Goff, not by chance, one of the most expressive representatives of the New History, very well-known by the Brazilian specialists. For so much, the following procedure was adopted: presentation of each of the propositions, extracted of the work History and Memory, and discussion of the same ones, relating them with the teaching, considered as knowledge production. The central subject, resulting from the group of the discussed prepositions, is the verification of the need of discussing teaching, as much as the research, to the light of the theoretical-methodological presuppositions and of the epistemology of the history. In the end, not as a conclusion but as a provocation to the debate, the general lines of the different school stages of the history teaching are presented, almost as established maxims, according to the current Brazilian legislation.
\end{abstract}

Key-words: History teaching, new history, historical knowledge production, teaching/research relation. 